\title{
Influence of para-orientating Methoxyl Units on the Electronic Structures and Light Absorption Properties of the Triphenylamine-based dyes by DFT Study
}

\author{
Guijie Liang, Jie Xu, ${ }^{\dagger}$ Weilin Xu,,$^{\dagger, *}$ Luoxin Wang, ${ }^{\dagger}$ Xiaolin Shen, ${ }^{\dagger}$ and Mu Yao \\ College of Materials Science \& Engineering, Xi'an Jiao tong University, Xi'an 710049, China. *E-mail: lgj511011@163.com \\ ${ }^{\dagger}$ Key Lab of Green Processing \& Functional Textiles of New Textile Materials, Ministry of Education, \\ Wuhan Textile University, Wuhan 430073, China. "E-mail: weilin-xu@hotmail.com \\ ${ }^{\ddagger} X i^{\prime}$ an Polytechnic University Xi'an 710049, China \\ Received August 26, 2010, Accepted May 23, 2011
}

\begin{abstract}
The geometries, electronic structures and absorption spectra of the two organic triphenylamine-based dyes TASt-CA and TA-DM-CA, containing identical electron donors and acceptors but the different conjugated bridges, were studied by density functional theory (DFT) at the B3LYP and PBE1PBE levels, respectively. The influence of para-orientating methoxyl units on the electronic structures and light absorption properties of the dyes and the consequent photovoltaic performance of the dye-sensitized solar cells (DSSCs) were investigated in detail. The results indicate that the introduction of the para-orientating methoxyl units into the conjugated bridge induces the increased absorption wavelength as well as the more negative $\mathrm{E}_{\mathrm{HOMO}}$ corresponding to the bigger driving force $\left(\mathrm{E}_{\mathrm{I}^{-} / \mathrm{I}_{3}^{-}}-\mathrm{E}_{\mathrm{HOMO}}\right)$ for dye reduction, which together improve the photovoltaic performance of TA-DM-CA, although there is a decline of the open circuit voltage caused by the more negative $\mathrm{E}_{\text {LUMO. }}$.
\end{abstract}

Key Words : Dye-sensitized solar cells, Density functional theory, Electronic structure, Absorption spectra

\section{Introduction}

Recently, with the increasingly serious energy-demanding and the environmental-concerning nature of conventional energy systems, dye-sensitized solar cells (DSSCs) have been intensively investigated as possible alternatives to conventional solid-state photovoltaic devices owing to their comparatively low cost and high efficiency. ${ }^{1-5}$ The dye acting as photosensitizer is one of the key factors for the light to energy conversion efficiency of the DSSCs. The performances of dyes, such as light harvesting efficiency, quantum yield of electron injection on the surface of semiconductor film, and so on, are of great importance to determine the efficiency of the DSSCs.

There are several types of dyes used in the DSSCs and among which polybipyridyl ruthenium complex dyes exhibit the relatively higher efficiency. ${ }^{6}$ Many metal-free organic dyes for the DSSCs, including cyanine dyes, ${ }^{7}$ indoline dyes $^{8,9}$ and coumarin dyes ${ }^{10}$ are also reported because of their lower cost, more environment harmony and more convenient synthesis process compared with the ruthenium complex dyes. These organic dyes have been experimentally proved as the promising sensitizers and have been synthesized and applied extensively for the DSSCs. Experimental synthesis method is a powerful and straightforward route to get new dyes; however, the process is not only expensive but also time-consuming. The density functional theory (DFT) calculation is another effective tool for theoretical treatment of structures as well as electronic and absorption spectra of the dyes. ${ }^{5,11-13}$ The theoretical studies of the physical properties of dyes are vital to disclose the relationship between the structures and the performance, which is advantageous for the dye screening and design.

In the past years, the novel organic dye TA-St-CA, containing a $\pi$-conjugated phenylenevinylene unit with an electron donor-acceptor moiety, was reported with the light to energy conversion efficiency of $9.1 \%{ }^{14,15}$ More recently, to enhance the electron donating character and absorption properties of the dye TA-St-CA, the dye TA-DM-CA, with the introduction of the para-orientating methoxyl units at the phenylenevinylene moiety, has been synthesized, yielding overall efficiency of $9.7 \% .{ }^{16}$ In order to understand the efficient sensitized mechanism of the dyes, and further to elucidate the photovoltaic performance enhancement of the dye induced by the para-orientating methoxyl units, the geometric and electronic structures and absorption properties of the dyes TA-St-CA and TA-DM-CA were investigated in detail via DFT and TD-DFT ${ }^{17,18}$ calculations. The relationships between the theoretical electronic parameters of the dyes and the experimental photovoltaic performance of the cells were also discussed.

\section{Computational Methods}

The structures of TA-St-CA and TA-DM-CA were preoptimized using the semi-empirical AM ${ }^{19}$ method. The final ground-state geometries were obtained by more precise optimization without any symmetry constrains at the Becke's three parameter gradient-corrected exchange potential and the Lee-Yang-Parr gradient-corrected correlation potential $(\mathrm{B} 3 \mathrm{LYP})^{20}$ level of theory with the $6-31 \mathrm{~g}(\mathrm{~d})$ basis set. A full natural bond orbital (NBO) analysis was employed by using the $\mathrm{POP}=\mathrm{NBO}$ keyword, along with the second-order perturbation theory (SOPT) approach. 
(a)

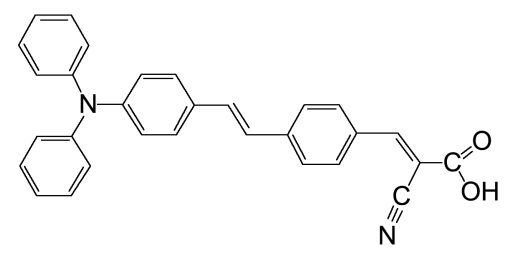

(b)

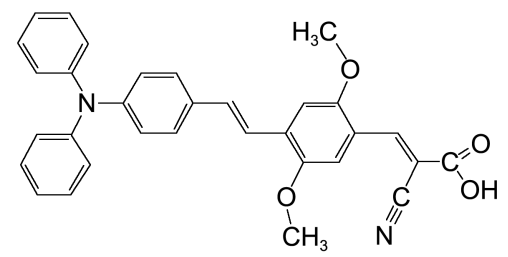

Figure 1. Chemical structures of the dyes: (a) TA-St-CA and (b) TA-DM-CA.

The excitation energies and oscillator strengths for the lowest 30 singlet-singlet transitions at the optimized geometry were obtained by TDDFT calculations ${ }^{21}$ with the hybrid functionals B3LYP and PBE1PBE, ${ }^{22}$ respectively, by the same basis set as for the ground state. According to the calculated results, the UV-vis absorption spectra were simulated by means of the SWizard program (Revision 4.6) using a Gaussian convolution with the full width at halfmaximum of $3500 \mathrm{~cm}^{-1}$.

The calculation was implied with the assumption that the dyes were involved in the ethanol solvent. Thus, the conductor polarizable continuum model (CPCM $)^{23}$ was employed in this program to introduce the solvation effect of ethanol. All calculations were performed with the Gaussian 03 program package. ${ }^{24}$

\section{Results and Discussion}

Molecular Geometries. As shown in Figure 1, the dyes of TA-St-CA and TA-DM-CA studied in this work all have a typical donor- $\pi$ conjugate-acceptor (D- $\pi$-A) structure, which contain phenylenevinylene or methoxy-substitued phenylenevinylene linker with the triphenylamine unit as an electron donor and cyanoacrylic acid as an acceptor. The structures of the two dyes are almost the same (the same donor and acceptor) except for the conjugated linkers, where exist the additional para-orientating methoxyl units for the TA-DM-CA compared with the TA-St-CA.

The optimized geometrical structures in the ground state of the dyes TA-St-CA and TA-DM-CA are given in Figure 2 , and the selected calculated bond lengths and dihedral angles of the dyes are listed in Table 1. The dihedral angles between the cyanoacrylic acid and the phenylenevinylene or the methoxy-substitued phenylenevinylene groups (TA-StCA: $\theta(47 \mathrm{C}-49 \mathrm{C}-34 \mathrm{C}-35 \mathrm{C})=179.77^{\circ}$, TA-DM-CA: $\theta(46 \mathrm{C}-$ $48 \mathrm{C}-34 \mathrm{C}-35 \mathrm{C})=179.34^{\circ}$ ) are all nearly to $180^{\circ}$, indicating the acceptor moiety (cyanoacrylic acid) is located to be coplanar with the groups in conjugate bridge (phenylenevinylene/methoxy-substitued phenylenevinylene) in the TA- (a) TA-St-CA

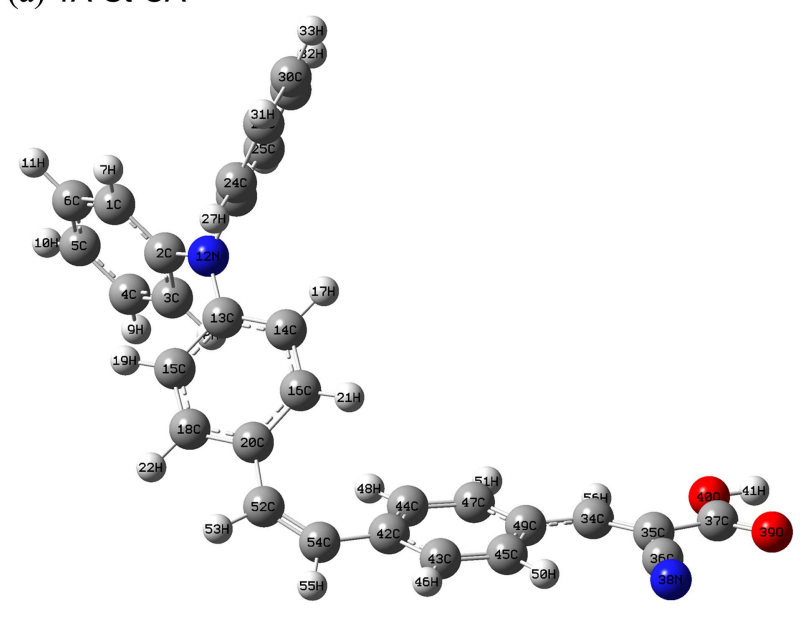

(b) TA-DM-CA

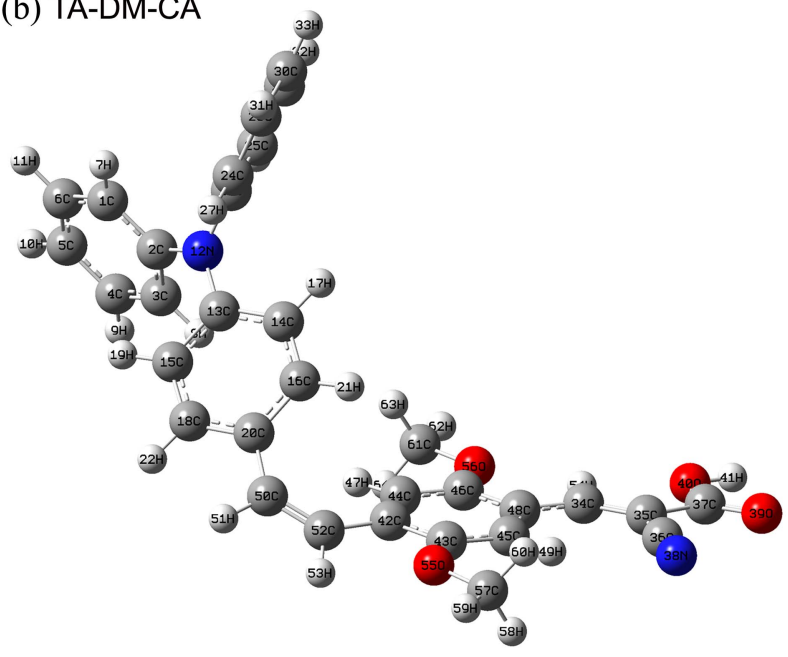

Figure 2. Optimized ground state geometries of (a) TA-St-CA and (b) TA-DM-CA with atomic serial numbers, at B3LYP/6-31g (d). (The red colored spheres: O; the blue colored spheres: $\mathrm{N}$; the larger dark colored spheres: $\mathrm{C}$; the smaller light colored spheres: $\mathrm{H}$ ).

St-CA and the TA-DM-CA. Thus, the strong conjugated effects may be formed in the structures of the two dyes which are very helpful for efficient charge transfer (CT) in the conjugated chains. The acceptor and donor moieties are practically identical in the two dyes, as demonstrated by the

Table 1. Selected bond lengths $(\AA)$ and dihedral angles $\left(^{\circ}\right)$ of TASt-CA and TA-DM-CA dyes, at B3LYP/6-31g (d)

\begin{tabular}{llll}
\hline TA-St-CA & \multicolumn{3}{l}{ TA-DM-CA } \\
\hline $\mathrm{R}^{a}(12 \mathrm{~N}-37 \mathrm{C})$ & 14.756 & $\mathrm{R}^{a}(12 \mathrm{~N}-37 \mathrm{C})$ & 14.797 \\
$\mathrm{R}^{a}(42 \mathrm{C}-53 \mathrm{C})$ & 1.455 & $\mathrm{R}^{a}(42 \mathrm{C}-51 \mathrm{C})$ & 1.455 \\
$\mathrm{R}^{a}(34 \mathrm{C}-49 \mathrm{C})$ & 1.443 & $\mathrm{R}^{a}(34 \mathrm{C}-48 \mathrm{C})$ & 1.435 \\
$\mathrm{R}^{a}(20 \mathrm{C}-52 \mathrm{C})$ & 1.456 & $\mathrm{R}^{a}(20 \mathrm{C}-50 \mathrm{C})$ & 1.455 \\
$\theta^{b}(52 \mathrm{C}-53 \mathrm{C}-42 \mathrm{C}-44 \mathrm{C})$ & 179.14 & $\theta^{b}(50 \mathrm{C}-51 \mathrm{C}-42 \mathrm{C}-43 \mathrm{C})$ & 165.31 \\
$\theta^{b}(47 \mathrm{C}-49 \mathrm{C}-34 \mathrm{C}-35 \mathrm{C})$ & 179.77 & $\theta^{b}(46 \mathrm{C}-48 \mathrm{C}-34 \mathrm{C}-35 \mathrm{C})$ & 179.34 \\
$\theta^{b}(18 \mathrm{C}-52 \mathrm{C}-53 \mathrm{C}-42 \mathrm{C})$ & 179.55 & $\theta^{b}(18 \mathrm{C}-50 \mathrm{C}-51 \mathrm{C}-42 \mathrm{C})$ & 177.70 \\
\hline
\end{tabular}

${ }^{a}$ The band length of the selected atoms. ${ }^{b}$ Dihedral angle of the two planes composed of the atoms involved above. 
very similar computed internal structural parameters. However, for TA-St-CA, the calculated distance between the C atom in carboxyl and the $\mathrm{N}$ atom in aniline is $11.55 \AA$, this value is larger about $0.16 \AA$ than that of the TA-DM-CA $(\mathrm{R}(12 \mathrm{~N}-37 \mathrm{C})=11.39 \AA)$, which reason may be designated to the electron delocalization effect induced by the additional para-orientating methoxyl units in the covalent linker of TADM-CA (will be further discussed in the following).

Electronic Structures. Natural bond orbital (NBO) analysis was carried out to analyze the charge populations of the dyes. The natural charges of triphenylaniline group (donor), phenylenevinylene group (covalent linker) and cyanoacrylic acid (acceptor) in TA-St-CA are 0.050, 0.075 and -0.125 , whereas those of triphenylaniline, phenylenevinylene, paraorientating methoxyl units and cyanoacrylic acid in TA-DMCA are $0.043,0.490,-0.389$ and -0.154 , respectively. The above data reveal that the para-orientating methoxyl units are not the effective electron donor unit, but the introduction of the para-orientating methoxyl units can bring both obvious enhancement of the electron-drawing capability to the acceptor and the electron-donating capability to the covalent linker, which are good for the electron CT process from dye to $\mathrm{TiO}_{2}$ conduction band, although a slight weakness to the electron-donating capability of the donor. In order to further characterize the CT capability of TA-DM$\mathrm{CA}$ and TA-St-CA, a second-order perturbation theory (SOPT) analysis of the Fock matrix within the NBO basis was carried out. The energies of the $\pi \rightarrow \pi^{*}$ conjugative interactions in the selected bonds taken from the NBO analysis are given in Table 2. As shown by NBO analysis, some of the energies of the conjugative interactions [TA-StCA: $\pi(\mathrm{C} 52=\mathrm{C} 53) \rightarrow \pi^{*}(\mathrm{C} 42=\mathrm{C} 44)$ vs. TA-DM-CA: $\pi(\mathrm{C} 50$ $\left.=\mathrm{C} 51) \rightarrow \pi^{*}(\mathrm{C} 42=\mathrm{C} 44)\right]$ are stronger in TA-St-CA but most of them are stronger in TA-DM-CA, implying that the conjugation effect of the D- $\pi-A$ system of TA-DM-CA increases compared with TA-St-CA, by introduction of the para-orientating methoxyl units. Then, the CT capability of TA-DM-CA will be improved accordingly.

The frontier molecular orbital (MO) contribution is very important in determining the charge-separated states of dyes. The MO of the dyes involved in the analyzed transition was examined in detail and the isodensity plots of TA-St-CA and TA-DM-CA are displayed in Figure 3. As to TA-St-CA, the highest occupied MO (HOMO) is mainly delocalized at the triphenylinaniline and the connected ethylene group, whereas the HOMO-1 is delocalized over the entire molecule. The lowest unoccupied MO (LUMO) is $\pi^{*}$ orbital localized in the cyanoacrylic acid and the phenylenevinylene with less contributions in the phenyl group in the triphenylinaniline linked to the vinyl group, whereas the LUMO +1 is also a $\pi^{*}$ orbital that localized in cyanoacrylic acid, phenylenevinylene and the connected phenylinaniline. As to TA-DM-CA, for the HOMO-1, HOMO and LUMO+1, there are some changes of electron density distribution in the phenyl group linked to the cyanoacrylic acid compared with those of TASt-CA, especially for the HOMO, the electron density in the phenyl group of the covalent linker connected to the cyanoacrylic acid increases largely (consistent with the NBO

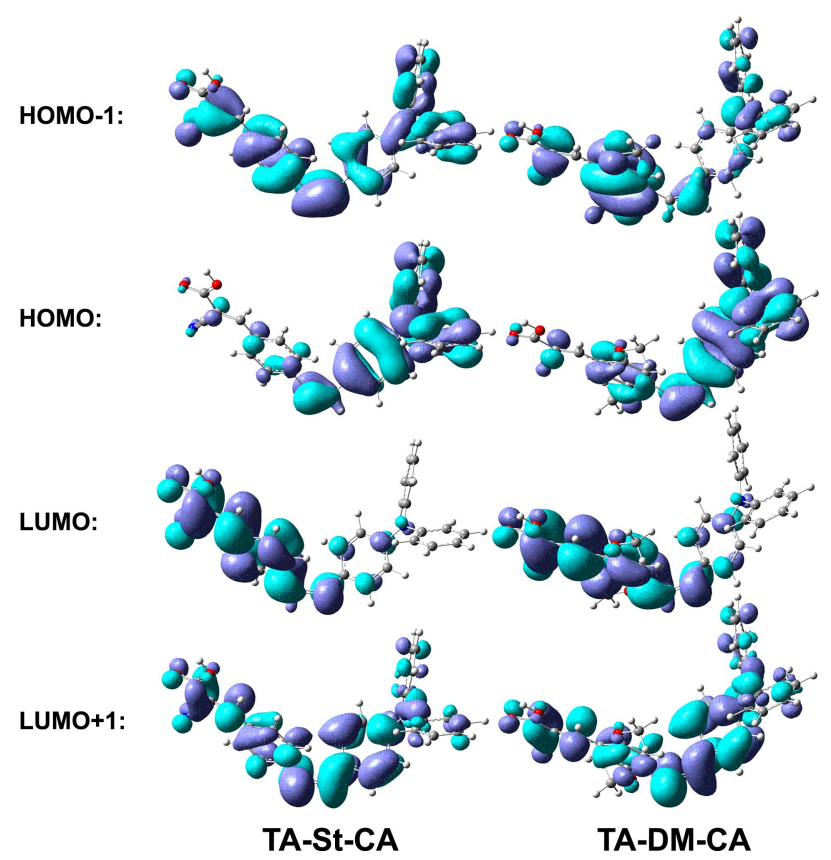

Figure 3. The frontier orbitals of TA-St-CA and TA-DM-CA optimized with DFT.

Table 2. Energy of conjugative interactions (in $\mathrm{kcal} / \mathrm{mol}$ ) between the $\pi$-bonding and $\pi^{*}$-antibonding orbitals in TA-St-CA and TA-DM-CA based on second-order perturbation theory analysis of the Fock matrix for the NBO analysis

\begin{tabular}{cccr}
\hline \multicolumn{1}{c}{ TA-St-CA } & \multicolumn{2}{c}{ TA-DM-CA } \\
\hline Type interaction & $\Delta \mathrm{E}(\mathrm{kcal} / \mathrm{mol})$ & \multicolumn{1}{c}{ Type interaction } & \multicolumn{1}{c}{$(\mathrm{kcal} / \mathrm{mol})$} \\
\hline$\pi(\mathrm{C} 52=\mathrm{C} 53) \rightarrow \pi^{*}(\mathrm{C} 16=\mathrm{C} 20)$ & 14.68 & $\pi(\mathrm{C} 50=\mathrm{C} 51) \rightarrow \pi^{*}(\mathrm{C} 18=\mathrm{C} 20)$ & 15.14 \\
$\pi(\mathrm{C} 52=\mathrm{C} 53) \rightarrow \pi^{*}(\mathrm{C} 42=\mathrm{C} 43)$ & 2.01 & $\pi(\mathrm{C} 50=\mathrm{C} 51) \rightarrow \pi^{*}(\mathrm{C} 42=\mathrm{C} 43)$ & 2.19 \\
$\pi(\mathrm{C} 52=\mathrm{C} 53) \rightarrow \pi^{*}(\mathrm{C} 42=\mathrm{C} 44)$ & 22.36 & $\pi(\mathrm{C} 46=\mathrm{C} 48) \rightarrow \pi^{*}(\mathrm{C} 34=\mathrm{C} 35)$ & 21.35 \\
$\pi(\mathrm{C} 47=\mathrm{C} 49) \rightarrow \pi^{*}(\mathrm{C} 34=\mathrm{C} 35)$ & 37.61 & $\pi(\mathrm{C} 34=\mathrm{C} 35) \rightarrow \pi^{*}(\mathrm{C} 36=\mathrm{C} 38)$ & 39.62 \\
$\pi(\mathrm{C} 34=\mathrm{C} 35) \rightarrow \pi^{*}(\mathrm{C} 36=\mathrm{C} 38)$ & 28.48 & $\pi(\mathrm{C} 34=\mathrm{C} 35) \rightarrow \pi^{*}(\mathrm{C} 37=\mathrm{C} 39)$ & 30.16 \\
$\pi(\mathrm{C} 34=\mathrm{C} 35) \rightarrow \pi^{*}(\mathrm{C} 37=\mathrm{C} 39)$ & 34.06 & $\pi(\mathrm{C} 34=\mathrm{C} 35) \rightarrow \pi^{*}(\mathrm{C} 46=\mathrm{C} 48)$ & 35.96 \\
$\pi(\mathrm{C} 34=\mathrm{C} 35) \rightarrow \pi^{*}(\mathrm{C} 47=\mathrm{C} 49)$ & 10.53 & $\mathrm{LP}(\mathrm{O} 54) \rightarrow \pi^{*}(\mathrm{C} 43=\mathrm{C} 45)$ & 10.72 \\
& & $\mathrm{LP}(\mathrm{O} 55) \rightarrow \pi^{*}(\mathrm{C} 46=\mathrm{C} 48)$ & 34.16 \\
\end{tabular}




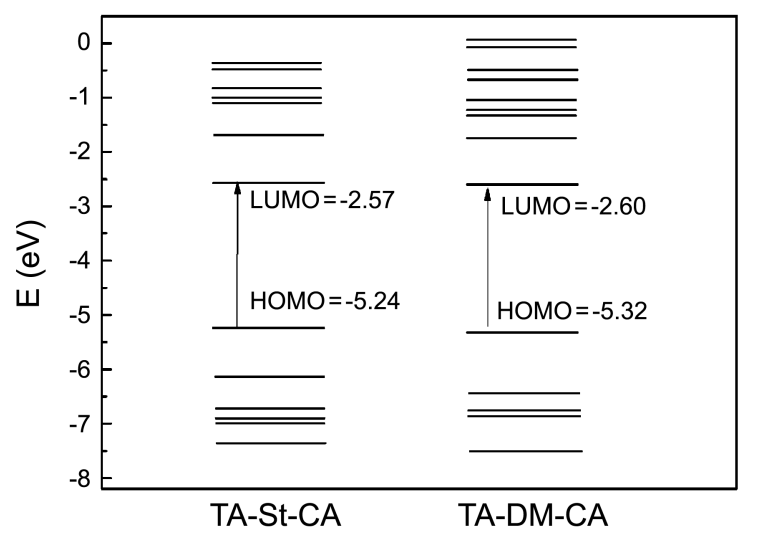

Figure 4. Frontier molecular orbital energies computed for TA-StCA and TA-DM-CA together with the $\mathrm{TiO}_{2}$ anatase (101) conduction band.

charge analysis, where the covalent linker became more charged by introduction of the para-orientating methoxyl units), while for the LUMO of TA-DM-CA, the electron density distribution throughout the dye molecule is almost similar to that of TA-St-CA. Consequently, with the higher electron density in the phenyl group of covalent linker, the electrons of TA-DM-CA will be easier to be separated and transferred from the more electron-rich linker to the acceptor moiety in comparison with TA-St-CA, which is in accord with the NBO and SOPT analysis above.

The calculated absolute energies of the HOMOs are -5.24 and $-5.35 \mathrm{eV}$, while those of the LUMOs are -2.58 and $-2.63 \mathrm{eV}$ respectively for TA-St-CA and TA-DM-CA, as shown in Figure 4. The LUMO levels of TA-St-CA and TADM-CA are sufficient more positive than the conduction band $(\mathrm{CB})$ energy level of $\mathrm{TiO}_{2}\left(\mathrm{E}_{\mathrm{cb}}\right.$ is $-2.77 \mathrm{eV}$ for the bare $\mathrm{Ti}_{38} \mathrm{O}_{76}$ cluster as a model for nanocrystalline exposing the anatase (101) surface ${ }^{25,26}$ ) to inject the electrons from the dyes to the conduction band of $\mathrm{TiO}_{2}$. Moreover, with the introduction of the para-orientating methoxyl units, the HOMO-LUMO energy gap of TA-DM-CA increases compared with that of TA-St-CA, which would be beneficial for the light absorption performance of TA-DM-CA.

Optical Absorption Spectra. The excitation energies and oscillator strengths for the lowest 30 singlet-singlet transitions dyes were calculated by TD-DFT method. In order to obtain the microscopic information about the electronic transitions, the corresponding molecular orbital properties were checked, and the excitation energies and oscillator strengths along with the main excitation configurations of TA-St-CA and TA-DM-CA by B3LYP and PBE1PBE are listed in Table 3 and 4, respectively.

On the basis of calculated electronic spectra, the UV-vis spectra of TA-St-CA and TA-DM-CA were simulated by a Gaussian convolution with the full width at half-maximum of $3500 \mathrm{~cm}^{-1}$, as shown in Figure 5. The simulated UV-vis spectra of TA-St-CA and TA-DM-CA both contain a very intense and broad band in the 500-700 $\mathrm{nm}$ region and one or two less intense bands in the $350-450 \mathrm{~nm}$ region. The spectrum of TA-DM-CA red-shifts in the long wavelength region $(500-700 \mathrm{~nm})$ while splits into two bands in the short wavelength region (350-450 nm) compared with that of TASt-CA, which are advantageous for the light harvesting for TA-DM-CA. The reason for the absorption difference between TA-St-CA and TA-DM-CA could be assigned to the enhancement of $\pi$ conjugation effect by introduction of the para-orientating methoxyl units to $p$-position of the basic

Table 3. Computed excitation energies, electronic transition configurations and oscillator strengths for the optical transitions with $\mathrm{f}_{\text {singlet }}>0.03$ of the UV-vis absorption bands for TA-St-CA and TA-DM-CA by B3LYP/6-31G (d)

\begin{tabular}{|c|c|c|c|c|}
\hline State & $\begin{array}{l}\text { Configurations composition with } \mid \text { CI Coeff. } \mid>0.2 \\
\text { (corresponding transition orbitalals) }\end{array}$ & $\begin{array}{l}\mathrm{E}_{\text {singlet }}^{a} \\
(\mathrm{eV} / \mathrm{nm})\end{array}$ & $\mathrm{f}^{b}{ }_{\text {singlet }}$ & Assign \\
\hline \multicolumn{5}{|c|}{ TA-St-CA } \\
\hline 1 & $\mathrm{H} \rightarrow \mathrm{L}(+90 \%)$ & $2.10 / 589.7$ & 1.090 & $\pi \rightarrow \pi^{*}$ \\
\hline 2 & $\mathrm{H}-1 \rightarrow \mathrm{L}(+82 \%) ; \mathrm{H} \rightarrow \mathrm{L}+1(9 \%)$ & $3.13 / 396.0$ & 0.841 & \\
\hline 3 & $\mathrm{H} \rightarrow \mathrm{L}+1(+80 \%) ; \mathrm{H}-1 \rightarrow \mathrm{L}(+6 \%)$ & $3.46 / 357.9$ & 0.144 & \\
\hline 4 & $\mathrm{H} \rightarrow \mathrm{L}+2(+55 \%) ; \mathrm{H}-3 \rightarrow \mathrm{L}(+36 \%)$ & $3.91 / 316.8$ & 0.033 & \\
\hline 5 & $\mathrm{H} \rightarrow \mathrm{L}+3(+86 \%)$ & $4.01 / 309.4$ & 0.172 & \\
\hline 6 & $\mathrm{H}-5 \rightarrow \mathrm{L}(+58 \%) ; \mathrm{H}-4 \rightarrow \mathrm{L}(18 \%) ; \mathrm{H}-1 \rightarrow \mathrm{L}+1(11 \%)$ & $4.15 / 298.4$ & 0.099 & \\
\hline 7 & $\mathrm{H} \rightarrow \mathrm{L}+5(+41 \%) ; \mathrm{H} \rightarrow \mathrm{L}+6(+38 \%) ; \mathrm{H} \rightarrow \mathrm{L}+7(9 \%)$ & $4.44 / 279.5$ & 0.032 & \\
\hline \multicolumn{5}{|c|}{ TA-DM-CA } \\
\hline 1 & $\mathrm{H} \rightarrow \mathrm{L}(+88 \%)$ & $2.06 / 600.7$ & 1.175 & $\pi \rightarrow \pi^{*}$ \\
\hline 2 & $\mathrm{H}-1 \rightarrow \mathrm{L}(+81 \%)$ & $2.74 / 452.6$ & 0.299 & \\
\hline 3 & $\mathrm{H}-2 \rightarrow \mathrm{L}(+83 \%)$ & $3.27 / 378.9$ & 0.4290 & \\
\hline 4 & $\mathrm{H} \rightarrow \mathrm{L}+1(+81 \%)$ & $3.46 / 357.8$ & 0.153 & \\
\hline 5 & $\mathrm{H} \rightarrow \mathrm{L}+2(+62 \%) ; \mathrm{H}-4 \rightarrow \mathrm{L}(+29 \%)$ & $3.90 / 317.8$ & 0.037 & \\
\hline 6 & $\mathrm{H} \rightarrow \mathrm{L}+3(+83 \%) ; \mathrm{H}-7 \rightarrow \mathrm{L}(8 \%)$ & $4.00 / 309.7$ & 0.162 & \\
\hline 7 & $\mathrm{H}-5 \rightarrow \mathrm{L}(+50 \%) ; \mathrm{H}-1 \rightarrow \mathrm{L}+1(37 \%)$ & $4.02 / 308.1$ & 0.038 & \\
\hline 8 & $\mathrm{H}-7 \rightarrow \mathrm{L}(+59 \%) ; \mathrm{H}-6 \rightarrow \mathrm{L}(+35 \%)$ & $4.17 / 297.4$ & 0.034 & \\
\hline 9 & $\mathrm{H} \rightarrow \mathrm{L}+5(+63 \%) ; \mathrm{H} \rightarrow \mathrm{L}+4(+20 \%)$ & $4.42 / 280.7$ & 0.036 & \\
\hline
\end{tabular}

${ }^{a}$ The excitation energies of the singlet-state for the dyes. ${ }^{b}$ The oscillator strengths of the singlet-state of the dyes. 
Table 4. Computed excitation energies, electronic transition conFigure urations and oscillator strengths (f) for the optical transitions with $\mathrm{f}_{\text {singlet }}>0.03$ of the UV-vis absorption bands for TA-St-CA and TA-DM-CA by PBE1PBE/6-31G (d)

\begin{tabular}{|c|c|c|c|c|}
\hline State & $\begin{array}{l}\text { Configurations composition with CI Coeff. }>0.2 \\
\text { (corresponding transition orbitalals) }\end{array}$ & $\begin{array}{c}\mathrm{E}_{\text {singlet }}^{a} \\
(\mathrm{eV} / \mathrm{nm})\end{array}$ & $\mathrm{f}^{b}{ }_{\text {singlet }}$ & Assign \\
\hline \multicolumn{5}{|c|}{ TA-St-CA } \\
\hline 1 & $\mathrm{H} \rightarrow \mathrm{L}(+90 \%)$ & $2.24 / 553.8$ & 1.213 & $\pi \rightarrow \pi^{*}$ \\
\hline 2 & $\mathrm{H}-1 \rightarrow \mathrm{L}(+84 \%) ; \mathrm{H} \rightarrow \mathrm{L}+1(7 \%)$ & $3.28 / 378.3$ & 0.764 & \\
\hline 3 & $\mathrm{H} \rightarrow \mathrm{L}+1(+82 \%)$ & $3.61 / 343.5$ & 0.154 & \\
\hline 4 & $\mathrm{H}-3 \rightarrow \mathrm{L}(+47 \%) ; \mathrm{H} \rightarrow \mathrm{L}+2(+30 \%) ; \mathrm{H} \rightarrow \mathrm{L}+3(+6 \%)$ & $4.10 / 302.1$ & 0.072 & \\
\hline 5 & $\mathrm{H} \rightarrow \mathrm{L}+3(+82 \%) ; \mathrm{H}-3 \rightarrow \mathrm{L}(10 \%)$ & $4.15 / 298.8$ & 0.167 & \\
\hline 6 & $\mathrm{H}-5 \rightarrow \mathrm{L}(+59 \%) ; \mathrm{H}-\rightarrow 6 \mathrm{~L}(+19 \%) ; \mathrm{H}-3 \rightarrow \mathrm{L}(6 \%)$ & $4.34 / 285.8$ & 0.063 & \\
\hline 7 & $\mathrm{H}-1 \rightarrow \mathrm{L}+1(+76 \%) ; \mathrm{H} \rightarrow \mathrm{L}+7(+10 \%)$ & $4.67 / 265.3$ & 0.039 & \\
\hline \multicolumn{5}{|c|}{ TA-DM-CA } \\
\hline 1 & $\mathrm{H} \rightarrow \mathrm{L}(+88 \%)$ & $2.18 / 568.1$ & 1.304 & $\pi \rightarrow \pi^{*}$ \\
\hline 2 & $\mathrm{H}-1 \rightarrow \mathrm{L}(+81 \%) ; \mathrm{H}-2 \rightarrow \mathrm{L}(+6 \%)$ & $2.84 / 436.0$ & 0.224 & \\
\hline 3 & $\mathrm{H}-2 \rightarrow \mathrm{L}(+80 \%) ; \mathrm{H} \rightarrow \mathrm{L}+1(+5 \%)$ & $3.42 / 362.8$ & 0.434 & \\
\hline 4 & $\mathrm{H} \rightarrow \mathrm{L}+1(+82 \%)$ & $3.61 / 343.8$ & 0.146 & \\
\hline 5 & $\mathrm{H}-3 \rightarrow \mathrm{L}(+62 \%) ; \mathrm{H}-4 \rightarrow \mathrm{L}(14 \%) ; \mathrm{H} \rightarrow \mathrm{L}+2(10 \%)$ & $4.07 / 304.4$ & 0.034 & \\
\hline 6 & $\mathrm{H}-4 \rightarrow \mathrm{L}(+32 \%) ; \mathrm{H} \rightarrow \mathrm{L}+2(+31 \%) ; \mathrm{H}-3 \rightarrow \mathrm{L}(+26 \%)$ & $4.08 / 303.5$ & 0.032 & \\
\hline 7 & $\mathrm{H} \rightarrow \mathrm{L}+3(+86 \%)$ & $4.15 / 299.0$ & 0.191 & \\
\hline 8 & $\mathrm{H} \rightarrow \mathrm{L}+5(+65 \%) ; \mathrm{H} \rightarrow \mathrm{L}+4(+15 \%)$ & $4.58 / 270.6$ & 0.042 & \\
\hline
\end{tabular}

${ }^{a}$ The excitation energies of the singlet-state for the dyes. ${ }^{b}$ The oscillator strengths of the singlet-state of the dyes.

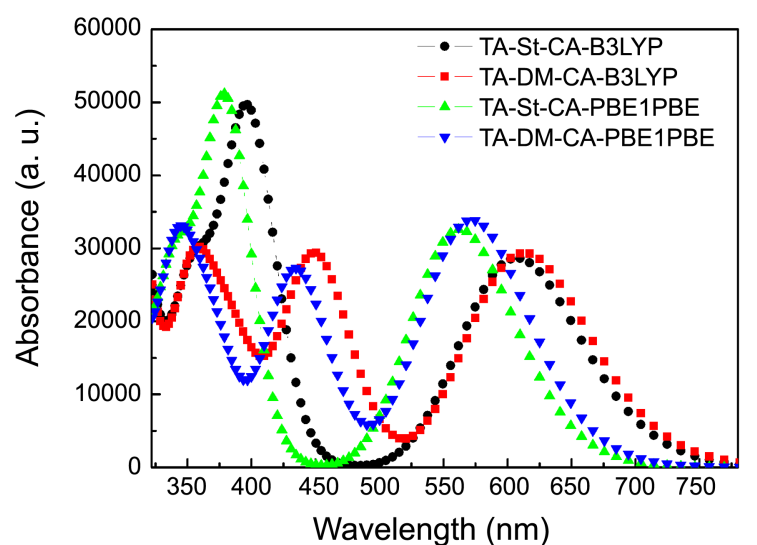

Figure 5. Simulated UV-vis absorption spectra of TA-St-CA and TA-DM-CA with hybrid functionals B3LYP and PBE1PBE.

phenylenevinylene structure (confirmed by the SOPT analysis). Furthermore, the absorption bands calculated by the B3LYP functional red-shift compared with that by the PBE1PBE for the two dyes.

The absorption peaks of the simulated spectra as well as the experimental results are summarized in Table 5. For TASt-CA, the experimental peaks are $302 \mathrm{~nm}$ (Peak I) and 386 nm (Peak II), while for TA-DM-CA the experimental peaks are $305 \mathrm{~nm}$ (Peak I) and $433 \mathrm{~nm}$ (Peak II). The calculated peaks of the dyes with B3LYP and PBE1PBE functionals are both red-shifted in comparison with the experimental. However, the qualitative agreements between the computed and the experimental peaks of the dyes can be obtained, although there are some discrepancy (red shift) between them which may be attributed to the DFT method and the solvent effects on the dyes. Moreover, the hybrid functional PBE1PBE is more suitable than B3LYP for calculation of
Table 5. The absorption peaks of the simulated as well as the experimental spectra of TA-St-CA and TA-DM-CA in ethanol

\begin{tabular}{lcccc}
\hline \multirow{2}{*}{ Dyes } & \multicolumn{4}{c}{$\lambda_{\text {abs }}(\mathrm{nm})$} \\
\cline { 2 - 5 } & & B3LYP & PBE1PBE & Experimental \\
\hline \multirow{2}{*}{ TA-St-CA } & Peak I & 393 & 375 & $302^{a}$ \\
& Peak II & 588 & 552 & $386^{a}$ \\
\hline \multirow{3}{*}{ TA-DM-CA } & Peak I & 374 & 359 & - \\
& Peak II & 452 & 434 & $305^{b}$ \\
& Peak II & 602 & 568 & $433^{b}$ \\
\hline
\end{tabular}

$\overline{{ }^{a} \text { The experimental absorption value from the Ref.14. }{ }^{b} \text { The experimental }}$ absorption value from the Ref.16.

electronic absorption spectra of the dyes in comparison with the experimental results, consulting from the Figure 5 and Table 5. As a whole, our computational method tends to be effective to deal with the UV-vis absorption spectra of the dyes.

Theoretical Parameters to Judge Electrochemical Performance of the Dyes. The electronic structures and absorption spectra of the TA-St-CA and TA-DM-CA were investigated by the DFT and TD-DFT calculations. The relationships between these electronic structure parameters and the photovoltaic performances of the dyes will be discussed in detail below.

According to the electron transfer mechanism and single electron and single state approximation, the following energy relationship exists: ${ }^{15}$

$$
\mathrm{eV}_{\mathrm{oc}}=\mathrm{E}_{\mathrm{LUMO}}-\mathrm{E}_{\mathrm{cb}}
$$

Where, $\mathrm{E}_{\mathrm{LUMO}}$ is the LUMO energy level $(\mathrm{eV})$ of the dyes, $E_{c b}$ is the conduction band energy level (eV) of the semiconductor and $\mathrm{V}_{\mathrm{oc}}$ is the open-circuit voltage $(\mathrm{V})$ of the 
Table 6. Photovoltaic performance and electronic structure parameters of TA-St-CA and TA-DM-CA

\begin{tabular}{lccccccc}
\hline Dyes & $\begin{array}{c}\mathrm{HOMO}^{a} \\
(\mathrm{eV})\end{array}$ & $\begin{array}{c}\mathrm{LUMO}^{a} \\
(\mathrm{eV})\end{array}$ & $\begin{array}{c}\mathrm{HOMO} \\
(\mathrm{eV})\end{array}$ & $\begin{array}{c}\mathrm{LUMO} \\
(\mathrm{eV})\end{array}$ & $\begin{array}{c}\mathrm{J}_{\mathrm{sc}} \\
\left.(\mathrm{mA} \mathrm{cm})^{-2}\right)\end{array}$ & $\begin{array}{c}\mathrm{V}_{\mathrm{oc}} \\
(\mathrm{mV})\end{array}$ & $\begin{array}{c}\eta(\%)^{b} \\
\text { dyes/N719 }\end{array}$ \\
\hline TA-St-CA & -5.24 & -2.58 & $-5.20^{c}$ & $-2.80^{c}$ & $18.1^{c}$ & $743^{c}$ & $9.1 / 10.1^{c}$ \\
TA-DM-CA & -5.35 & -2.63 & $-5.51^{d}$ & $-3.02^{d}$ & $20.9^{d}$ & $697^{d}$ & $9.7 / 10.2^{d}$ \\
\hline
\end{tabular}

${ }^{a}$ Calculated by B3LYP/6-31G (d). ${ }^{b}$ The conversion efficiency of the dyes at AM 1.5 illumination $\left(100 \mathrm{~mW} \mathrm{~cm}^{-2}\right)$, with comparison of N719 under the same conditions. ${ }^{c}$ Experiment value from Ref.14. ${ }^{d}$ Experiment value from Ref.16.

DSSCs. In Eq. (1), the $\mathrm{E}_{\mathrm{cb}}$ of $\mathrm{TiO}_{2}$ is $-2.77 \mathrm{eV}$, which is much more negative than the $\mathrm{E}_{\mathrm{LUMO}}$ values of $-2.58 \mathrm{eV}$ for TA-St-CA and $-2.63 \mathrm{eV}$ for TA-DM-CA, as shown in Figure 4. According to the equation, the more positive $\mathrm{E}_{\text {LUMO }}$ of the dyes means the bigger $\mathrm{V}_{\mathrm{oc}}$ of the cells. Then, the TA-St-CA, with the more positive $\mathrm{E}_{\mathrm{LUMO}}$, has a bigger $\mathrm{V}_{\text {oc }}(743 \mathrm{mV})$ than that $(679 \mathrm{mV})$ of TA-DM-CA. On the other hand, the short circuit current density $\left(\mathrm{J}_{\mathrm{sc}}\right)$ is determined by not only the rate of electron injection from the excited dyes to the conduction band of $\mathrm{TiO}_{2}$, but also the rate of reduction between the excited dyes and $\mathrm{I}^{-} / \mathrm{I}_{3}{ }^{-}$. The more negative $\mathrm{E}_{\mathrm{HO} \mathrm{MO}}$ corresponds to the much bigger driving force $\left(\mathrm{E}_{\mathrm{I}^{-} / I_{3}^{-}}-\mathrm{E}_{\text {Hомо }}\right)$ for the reduction of the oxidized dye by $\mathrm{I}^{-}$in the electrolyte and the faster rate for the reduction of the oxidized dye. So, with the $\mathrm{E}_{\text {Hомо }}$ of $-5.24 \mathrm{eV}$ for TA-St$\mathrm{CA}$ and $-5.35 \mathrm{eV}$ for TA-DM-CA, the theoretical order of the short circuit current density of the dyes is $\mathrm{J}_{\mathrm{sc}}$ (TA-DMCA) $>J_{\mathrm{sc}}(\mathrm{TA}-\mathrm{St}-\mathrm{CA})$, which is consistent with the experiment results in Table 6. Additionally, with the introduction of the para-orientating methoxy units, the absorption wavelength of TA-DM-CA increases compared with that of TASt-CA, revealing better light absorption efficiency for TADM-CA. In sum, taking all factors above into consideration, the light-to-electric conversion efficiency of TA-DM-CA $\left(9.7 / 10.2 \%{ }^{16}\right)$ is slightly higher than that of TA-St-CA $(9.1 /$ $10.1 \%{ }^{14}$ ), with the N719 as reference under the same conditions.

\section{Conclusions}

A detailed theoretical study of the geometric and electronic properties of TA-St-CA and TA-DM-CA as efficient sensitizers for the DSSCs has been performed. The calculated geometric characters indicate that the strong conjugated effects between the acceptor moiety and the conjugate bridge are formed, which are very helpful for efficient electron transfer in the conjugated chains in the two dyes. The calculated electronic properties display the HOMO and the LUMO levels of the dyes match well with the energy levels of the $\mathrm{TiO}_{2}$ for the electron transfer in the DSSCs. The simulated absorption spectra of the dyes agree with those of the experiment. The comparative studies of electronic structures and absorption spectra between TA-St-CA and TADM-CA indicate that with introduction of the para-orientating methoxyl units into the conjugated bridge, the HOMO and LUMO energy levels of TA-DM-CA become negative while the HOMO-LUMO energy gap of it widens; and the simulated absorption wavelength increases in comparison with that of TA-St-CA.

Through the theoretical analysis between the photovoltaic performance and electronic structure parameters, the smaller $\mathrm{V}_{\mathrm{oc}}$ of TA-DM-CA may be deduced by the more negative

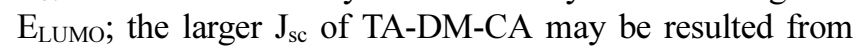
the increased absorption wavelength and the bigger reduction driving force caused by the much more negative $\mathrm{E}_{\text {Hомо }}$; and the common effects make the TA-DM-CA a more efficient sensitizer than the TA-St-CA for the DSSCs, which is consistent with the experiment results.

Acknowledgments. This work was financially supported by the Key Project of Science and Technology Research of Ministry of Education (No. 208089), the Natural Science Foundation of Hubei Province (No. 2007ABA075 and No. 2008CDB261) and the Educational Commission of Hubei Province (Q20101606).

\section{References}

1. Oregan, B.; Gräzel, M. Nature 1991, 353, 737.

2. Papageorgiou, N.; Gräzel, M.; Infelta, P. P. Sol. Energy Mater. Sol. Cells 1996, 44, 405.

3. Hagfeldt, A.; Gratzel, M. Acc. Chem. Res. 2000, 33, 269.

4. Kuang, D.; Klein, C.; Snaith, H. J.; Humphry-Baker, R.; Zakeeruddin, S. M.; Gräzel, M. Inorg. Chim. Acta 2008, 361, 699.

5. Liu, Z. Theochem-J. Mol. Struct. 2008, 862, 44.

6. Nazeeruddin, M. K.; Pechy, P.; Renouard, T.; Zakeeruddin, S. M.; Humphry-Baker, R.; Comte, P.; Liska, P.; Cevey, L.; Costa, E.; Shklover, V.; Spiccia, L.; Deacon, G. B.; Bignozzi, C. A.; Gratzel, M. J. Am. Chem. Soc. 2001, 123, 1613.

7. Guo, M.; Diao, P.; Ren, Y.-J.; Meng, F.; Tian, H.; Cai, S.-M. Sol. Energy Mater. Sol. Cells 2005, 88, 23.

8. Horiuchi, T.; Miura, H.; Sumioka, K.; Uchida, S. J. Am. Chem. Soc. 2004, 126, 12218.

9. Diao, L. Y.; Gu, W. X.; Chen, Y. H.; Ma, F. C. Chin. J. Chem. Phys. 2006, 19, 238.

10. Enea, O.; Moser, J.; Gräzel, M. J. Electroanal. Chem. 1989, 259, 59.

11. Ma, R. M.; Guo, P.; Yang, L. L.; Guo, L. S.; Zeng, Q. H.; Liu, G. Q.; Zhang, X. X. Theochem-J. Mol. Struct. 2001, 942, 131.

12. Balanay, M. P.; Kim, D. H. Phys. Chem. Chem. Phys. 2008, 10, 5121.

13. De Angelis, F.; Fantacci, S.; Selloni, A. Nanotechnology 2008, 19, 424002.

14. Hwang, S.; Lee, J. H.; Park, C.; Lee, H.; Kim, C.; Lee, M. H.; Lee, W.; Park, J.; Kim, K.; Park, N. G. Chem. Commun. 2007, 4887.

15. Zhang, C.-R.; Liu, Z.-J.; Chen, Y.-H.; Chen, H.-S.; Wu, Y.-Z.; Feng, W.; Wang, D.-B. Curr. Appl. Phys. 2010, 10, 77.

16. Im, H.; Kim, S.; Park, C.; Jang, S. H.; Kim, C. J.; Kim, K.; Park, N. G.; Kim, C. Chem. Commun. 2010, 46, 1335.

17. Stratmann, R. E.; Scuseria, G. E.; Frisch, M. J. J. Chem. Phys. 1998, 109, 8218. 
18. Hirata, S.; Head-Gordon, M. Chem. Phys. Lett. 1999, 302, 375.

19. Télez, S. C. A.; Hollauer, E.; Giannerini, T.; Pais da Silva, M. I.; Mondragón, M. A.; Rodríguez, T. J. R.; Castaño, V. M. Spectrochim. Acta, Part A 2004, 60, 2171.

20. Becke, A. D. J. Chem. Phys. 1993, 98, 5648.

21. Tiwary, A. S.; Mukherjee, A. K. Theochem-J. Mol. Struct. 2008, 859, 107.

22. Perdew, J. P.; Burke, K.; Ernzerhof, M. Phys. Rev. Lett. 1996, 77, 3865.

23. Cossi, M.; Barone, V.; Cammi, R.; Tomasi, J. Chem. Phys. Lett. 1996, 255,327

24. Frisch, M. J.; Trucks, G. W.; Schlegel, H. B.; Scuseria, G. E.; Robb, M. A.; Cheeseman, J. R.; Montgomery, J. A., Jr.; Vreven, T.; Kudin, K. N.; Burant, J. C.; Millam, J. M.; Iyengar, S. S.; Tomasi, J.; Barone, V.; Mennucci, B.; Cossi, M.; Scalmani, G.; Rega, N.; Petersson, G. A.; Nakatsuji, H.; Hada, M.; Ehara, M.; Toyota, K.; Fukuda, R.; Hasegawa, J.; Ishida, M.; Nakajima, T.;
Honda, Y.; Kitao, O.; Nakai, H.; Klene, M.; Li, X.; Knox, J. E.; Hratchian, H. P.; Cross, J. B.; Bakken, V.; Adamo, C.; Jaramillo, J.; Gomperts, R.; Stratmann, R. E.; Yazyev, O.; Austin, A. J.; Cammi, R.; Pomelli, C.; Ochterski, J. W.; Ayala, P. Y.; Morokuma, K.; Voth, G. A.; Salvador, P.; Dannenberg, J. J.; Zakrzewski, V. G.; Dapprich, S.; Daniels, A. D.; Strain, M. C.; Farkas, O.; Malick, D. K.; Rabuck, A. D.; Raghavachari, K.; Foresman, J. B.; Ortiz, J. V.; Cui, Q.; Baboul, A. G.; Clifford, S.; Cioslowski, J.; Stefanov, B. B.; Liu, G.; Liashenko, A.; Piskorz, P.; Komaromi, I.; Martin, R. L.; Fox, D. J.; Keith, T.; Al-Laham, M. A.; Peng, C. Y.; Nanayakkara, A.; Challacombe, M.; Gill, P. M. W.; Johnson, B.; Chen, W.; Wong, M. W.; Gonzalez, C.; Pople, J. A. Gaussian 03; Revision E.01, Gaussian, Inc.: Wallingford CT, 2004.

25. De Angelis, F.; Tilocca, A.; Selloni, A. J. Am. Chem. Soc. 2004, 126,15024

26. Xu, J.; Zhang, H.; Liang, G. J.; Wang, L. X.; Xu, W. L.; Cui, W. G.; Li, Z. C. J. Serb. Chem. Soc. 2010, 75, 259. 